Research Article

\title{
Shaking Table Test Study on Seismic Performance of Hollow Rectangular Piers
}

\author{
Yanli Shen (iD) and Bo Wei \\ Hebei University of Engineering, Handan 056038, China \\ Correspondence should be addressed to Yanli Shen; shenyanli@hebeu.edu.cn
}

Received 9 June 2019; Accepted 28 July 2019; Published 22 August 2019

Guest Editor: André Furtado

Copyright (c) 2019 Yanli Shen and Bo Wei. This is an open access article distributed under the Creative Commons Attribution License, which permits unrestricted use, distribution, and reproduction in any medium, provided the original work is properly cited.

\begin{abstract}
To study the seismic performance of hollow reinforced concrete piers under dynamic loads, nine hollow pier specimens with different stirrup ratios, reinforcement ratios, and axial compression ratios are designed and manufactured. The El Centro wave, Taft wave, and artificial Lanzhou wave are selected as seismic excitation for the shaking table test. The effects of the reinforcement ratio, stirrup ratio, and axial compression ratio on the failure mode, period, damping, acceleration and displacement response, dynamic magnification factor, ductility, and energy dissipation of specimens under different working conditions are studied. The results show that all the nine reinforced concrete piers have good seismic performance. Subjected to ground motion excitation, horizontal through cracks appeared on the pier surface. With the increase of ground motion excitation, the period of piers increases but the maximum period does not exceed $0.62 \mathrm{~s}$, and the damping ratio increases as well and ranges from 0.02 to 0.064 . With the increase of the ground motion excitation, the acceleration response of pier specimens increases, the dynamic magnification factor decreases, the displacement ductility coefficient decreases, and the energy dissipation of the specimens increases. The reinforcement ratio, stirrup ratio, and axial compression ratio have different effects on the above parameters. The test results can provide reference for seismic design of hollow rectangular piers and have certain engineering significance and value.
\end{abstract}

\section{Introduction}

Hollow section is the ideal section form of piers. Hollow section can bring maximum benefit to the structure, and it will also reduce the influence of pier self-weight on bridge seismic response [1]. Therefore, hollow piers are widely used in engineering, so it is important to strengthen the research of hollow piers.

However, most shaking table tests have been carried out for solid piers. Matthew [2], according to the American seismic design code, designed and manufactured a full-scale circular solid section reinforced concrete pier, eliminating the influence of size effect, and studied the whole process of pier failure. Sakai and Unjoh [3] carried out multidimensional seismic simulation shaking table tests on circular solid piers and analysed the failure mechanism of piers. Calvi et al. [4] focused on some relevant aspects of the damage development and collapse modes of hollow piers, such as absence of confinement, inadequate shear strength, shifting of the critical section, and insufficient length of lap splices. Mo et al. [5-8] and Pinto et al. [9] studied the seismic performance of hollow rectangular section RC piers and gave the corresponding prediction models of seismic response of these piers according to the design codes of the authors' country. Cassese et al. $[10,11]$ designed and realized four concrete bridge piers with a hollow rectangular section with different shear span-to-section depth ratios to test the seismic performance of existing piers. Si and Ai $[12,13]$ carried out the pseudostatic test and shaking table test on reinforced concrete pier specimens. The experimental results verified that the reinforced concrete pier based on the displacement design method can meet the expected ductility seismic requirements. Wang [14] and Zhou [15], respectively, input unidirectional and bidirectional ground motion excitations to conduct shaking table tests on roundend solid piers of high-speed railways and studied the influence of the reinforcement ratio and shear span ratio on solid piers of railways. Most of the studies on hollow 
rectangular piers are based on pseudostatic tests at home and abroad. Shaking table tests on hollow piers are rare. Shen and $\mathrm{Gu}$ [16] designed and manufactured two hollow high pier with different stirrup ratios. Shaking table tests were carried out to study the seismic response of piers under different earthquake excitations. Du et al. [17] made five large-scale hollow reinforced concrete pier specimens and carried out cyclic load tests to evaluate their seismic performance. Jiang et al. $[18,19]$ carried out cyclic load tests and shaking table tests on large-scale hollow pier specimens and discussed the influence of pier height, axial compression ratio, and other factors on pier ductility. Han et al. [20] designed and manufactured 12 hollow rectangular RC piers, carried out cyclic load tests, and established a fiber model. The tests showed that the ductility coefficient and the equivalent viscous damping ratio of the specimens meet the requirements of seismic design and all the specimens had good seismic performance. However, the actual earthquake motion process is a complex vibration process. The pseudostatic loading test ignores the influence of loading rate on the structural strength and stiffness characteristics and fails to reflect the seismic performance of components in actual vibration. Therefore, the pseudostatic loading test has great limitations [21]. Therefore, it is necessary to carry out shaking table tests for hollow rectangular piers to study the failure mechanism of the pier structure, analyse its failure mode, and evaluate its seismic performance.

To study the seismic performance of hollow piers under dynamic loading, nine hollow rectangular reinforced concrete piers with different stirrup ratios, reinforcement ratios, and axial compression ratios were designed and manufactured. Shaking table tests were carried out to study the failure mode, dynamic characteristics, acceleration and displacement response, dynamic magnification factor, ductility, and energy dissipation of hollow rectangular piers. This paper focuses on the failure mode and response analysis of shaking table tests on hollow piers. It can provide reference for performance-based seismic design of hollow piers.

\section{Shaking Table Test Design}

2.1. Similarity Constants. In this study, the prototype of pier was a hollow pier in engineering. The height of the prototype pier was $11.5 \mathrm{~m}$. Considering the loading capacity of the shaking table in the laboratory and the limitation of test conditions, the length similarity constant was $1: 8$. Other similarity constant were deduced and calculated according to the general similitude law [22]. The specific values are shown in Table 1.

2.2. Model Design and Construction. Nine hollow piers were designed and manufactured in this test. The pier numbers were M1, M2, M3, M4, M5, M6, M7, M8, and M9, and their geometric dimensions were identical. According to the length similarity constant, the pier height of the tested specimens was $1.44 \mathrm{~m}$. The cross section of the specimens was $180 \times 250 \mathrm{~mm}$, the inner hollow part was $60 \times 130 \mathrm{~mm}$, and the wall thickness was $60 \mathrm{~mm}$. Three views of the pier are shown in Figure 1. Concrete strength grade of the pier model was C20. The
TABLE 1: Similarity constants.

\begin{tabular}{lcc}
\hline Parameter & Similarity relation & $\begin{array}{c}\text { Similarity } \\
\text { ratio }\end{array}$ \\
\hline Length & $l_{r}$ & 0.125 \\
Elastic & $E_{r}$ & 0.78 \\
modulus & $\overline{\rho_{r}}=m_{m}+m_{a}+m_{o m} / l_{r}^{3}\left(m_{p}+m_{o p}\right)$ & 6.22 \\
Density & $\sigma_{r}=E_{r}$ & 0.78 \\
Stress & $r_{r}=l_{r}$ & 0.125 \\
Strain & $t_{r}=\sqrt{l_{r}^{2} \overline{\rho_{r}} / E_{r}}$ & 0.353 \\
Time & $v_{r}=\sqrt{E_{r} / \rho_{r}}$ & 0.354 \\
Velocity & $a_{r}=E_{r} / l_{r} \overline{\rho_{r}}$ & 1 \\
Acceleration & $\omega_{r}=\sqrt{E_{r} / l_{r}^{2} \overline{\rho_{r}}}$ & 2.83 \\
Frequency & &
\end{tabular}

diameter of the longitudinal reinforcement was $6 \mathrm{~mm}$ and $8 \mathrm{~mm}$, and the strength grade of the longitudinal reinforcement was HRB335. A galvanized iron wire with diameters of $3 \mathrm{~mm}$ and $4 \mathrm{~mm}$ was used for stirrups. Details of model specimens are shown in Figure 1. The mechanical properties of concrete and steel bars are listed in Tables 2 and 3, respectively. The physical parameters of each specimen are shown in Table 4. And the picture of the specimen is shown in Figure 2.

2.3. Counterweight Design. In this experiment, iron blocks were used to simulate the artificial mass, and the counterweight box was made to hold iron blocks and fixed on the top of the pier model. The counterweight box was welded with a Q235 steel plate of $5 \mathrm{~mm}$ thickness. The size of the counterweight box was $1.0 \mathrm{~m} \times 1.0 \mathrm{~m} \times 0.7 \mathrm{~m}$. In order to achieve a fixed connection with the top of the model specimen, a rectangular sleeve with a cross section of $0.3 \times 0.25 \mathrm{~m}$ and a height of $0.3 \mathrm{~m}$ was welded inside the counterweight box. The bolt holes were reserved at the top of the rectangular sleeve, and the bolts were reserved at the top of the model specimen through the nuts. The counterweight box weighed $200 \mathrm{~kg}$. The object of the counterweight box is shown in Figure 3.

2.4. Test Content and Layout of Test Points. Acceleration sensors and velocity sensors were arranged on the pier top and bottom of hollow pier specimens to record the acceleration and velocity responses of the pier top and bottom. An acceleration sensor was arranged on the platform to record the ground motion of the platform; five concrete strain gauges were arranged on the two sides of the vertical loading direction (transverse bridge direction) of the pier specimens. There were 10 concrete strain gauges, numbered $\mathrm{H} 1-\mathrm{H} 5$ and $\mathrm{H} 6-\mathrm{H} 10$, respectively, from bottom to top; three steel strain gauges were arranged on the bottom of the pier with longitudinal reinforcement at each corner. There were 12 steel strain gauges. The layout of specific measuring points is shown in Figure 4.

2.5. Ground Motion Waves and Loading Conditions. Three kinds of ground motion waves, El Centro wave, Taft wave, and artificial Lanzhou wave, were used as excitation in this experiment. Loading conditions are listed in Table 5. 


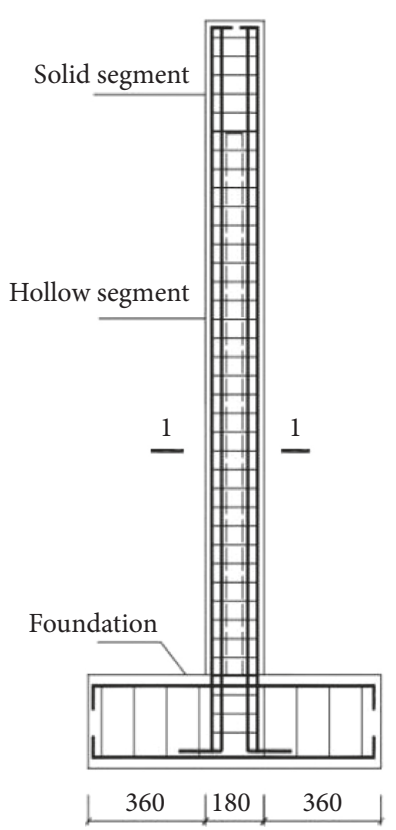

(a)
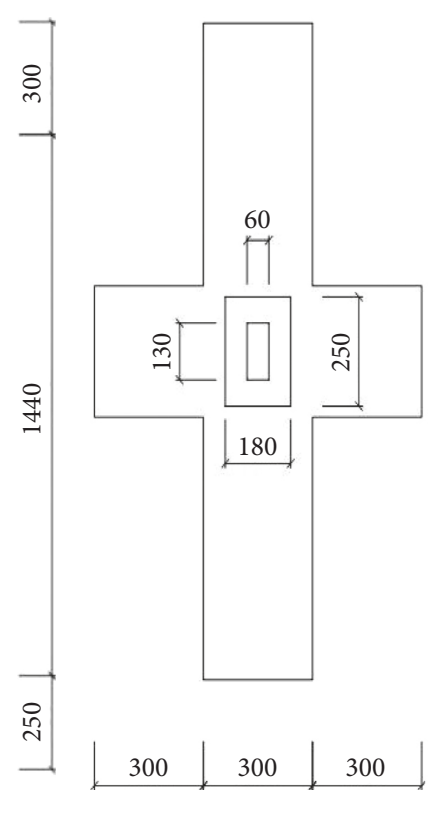

(b)

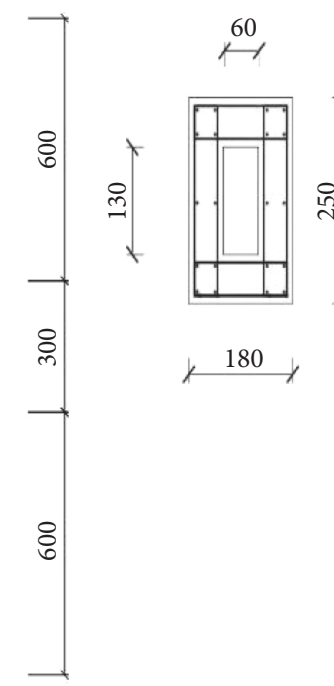

(c)

Figure 1: Details of the model specimen. (a) Front view. (b) Top view. (c) 1-1 cross sections.

TABLE 2: Mechanical properties of concrete.

\begin{tabular}{lcc}
\hline Strength grade & Compressive strength $(\mathrm{MPa})$ & Elastic modulus $(\mathrm{MPa})$ \\
\hline C20 & 13.4 & 18560 \\
C30 & 20.1 & 20000 \\
\hline
\end{tabular}

TABle 3: Mechanical properties of steel bars.

\begin{tabular}{lcccc}
\hline Diameter $(\mathrm{mm})$ & Yield strength $(\mathrm{MPa})$ & Tensile strength $(\mathrm{MPa})$ & Elongation $(\%)$ & Elastic modulus $(\mathrm{MPa})$ \\
\hline 8 & 389.1 & 614.4 & 8.1 & 194550 \\
6 & 385.3 & 613.8 & 8.5 & 192650 \\
4 & 383.4 & 601.4 & 9.1 & 191700 \\
3 & 383.2 & 577.2 & 8.8 & 191600 \\
\hline
\end{tabular}

TABLE 4: Detailed physical parameters of the specimen.

\begin{tabular}{|c|c|c|c|c|c|c|c|}
\hline \multirow[b]{2}{*}{ Specimen } & \multirow[b]{2}{*}{ Pier height $(\mathrm{mm})$} & \multirow[b]{2}{*}{ Axial compression ratio } & \multicolumn{2}{|c|}{ Longitudinal reinforcement } & \multicolumn{3}{|c|}{ Transverse reinforcement } \\
\hline & & & $\begin{array}{c}\text { Diameter } \\
(\mathrm{mm})\end{array}$ & $\begin{array}{c}\text { Reinforcement ratio } \\
(\%)\end{array}$ & Diameter $(\mathrm{mm})$ & $\begin{array}{c}\text { Distance } \\
(\mathrm{mm})\end{array}$ & $\begin{array}{c}\text { Stirrup ratio } \\
(\%)\end{array}$ \\
\hline M1 & 1440 & 0.1 & 8 & 2.7 & 4 & 50 (double) & 4.0 \\
\hline M2 & 1440 & 0.1 & 8 & 2.7 & 4 & 50 & 2.0 \\
\hline M3 & 1440 & 0.1 & 8 & 2.7 & 3 & 70 & 0.81 \\
\hline M4 & 1440 & 0.1 & 8 & 2.7 & 3 & 130 & 0.44 \\
\hline M5 & 1440 & 0.1 & 6 & 1.5 & 3 & 130 & 0.44 \\
\hline M6 & 1440 & 0.05 & 8 & 2.7 & 3 & 70 & 0.81 \\
\hline M7 & 1440 & 0.05 & 8 & 2.7 & 3 & 130 & 0.44 \\
\hline M8 & 1440 & 0.05 & 6 & 1.5 & 3 & 130 & 0.44 \\
\hline M9 & 1440 & 0.05 & 6 & 1.5 & 3 & 70 & 0.81 \\
\hline
\end{tabular}

\section{Results and Discussion}

3.1. Reappearance of Ground Motion Waves. Taking three waves in $0.75 \mathrm{~g}$ condition as an example, the theoretical value of the acceleration-time history curve and the measured value of the acceleration-time history curve of the platform were compared, as shown in Figure 5. It can be seen that the curve shapes of measured values and theoretical values are in good agreement, which shows that the performance of the shaking table is good. 


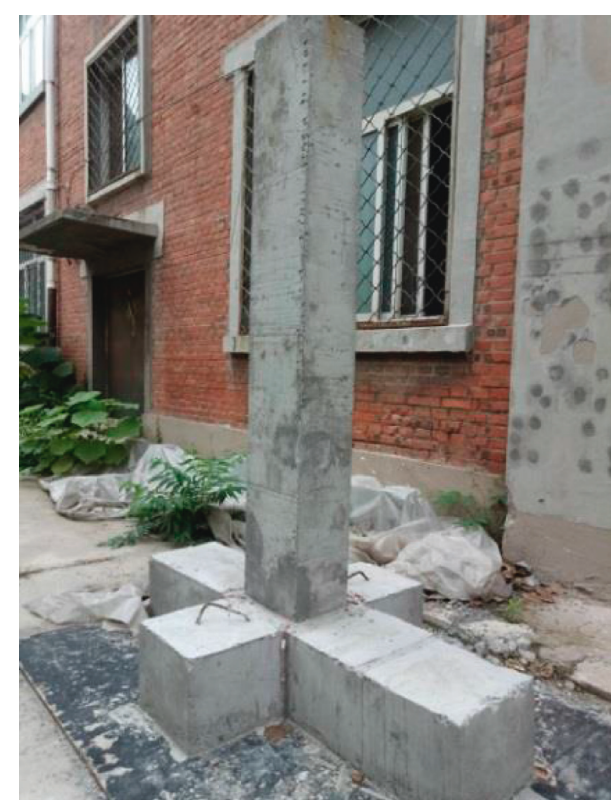

Figure 2: Picture of the pier specimen.

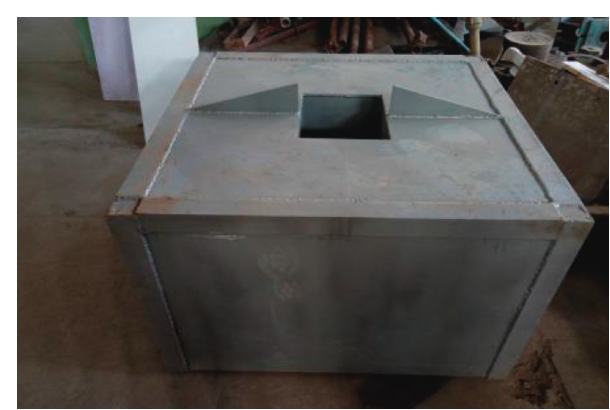

FIgURE 3: Counterweight box.

3.2. Failure Mode. All specimens began to crack at the bottom of the pier. With the increase of the peak acceleration of ground motion, cracks continued to extend upward, and the original cracks became wider and deeper. All pier specimens showed horizontal through cracks, and bridge piers were all bending failure. The specific failure modes of each specimen are shown in Table 6. The distribution of postearthquake cracks of pier specimens is shown in Figure 6.

3.3. Natural Vibration Period of Piers. The pier model of this experiment can be regarded as a single-degree-of-freedom system. When the input ground motion stops, the pier specimen will generate free vibration. The vibration period of the pier can be obtained by fast Fourier transform of the acceleration- or displacement-time history curve of the pier top at this stage. The period after each stage is shown in Figure 7.

From Figure 7, it can be seen that, with the increase of the input ground motion, the vibration period of each specimen increased, which indicated that the specimens were damaged under the effect of ground motion, and the stiffness of the specimens reduced. Comparing M1 and M2, M6 and M7, and M8 and M9, it was found that the vibration

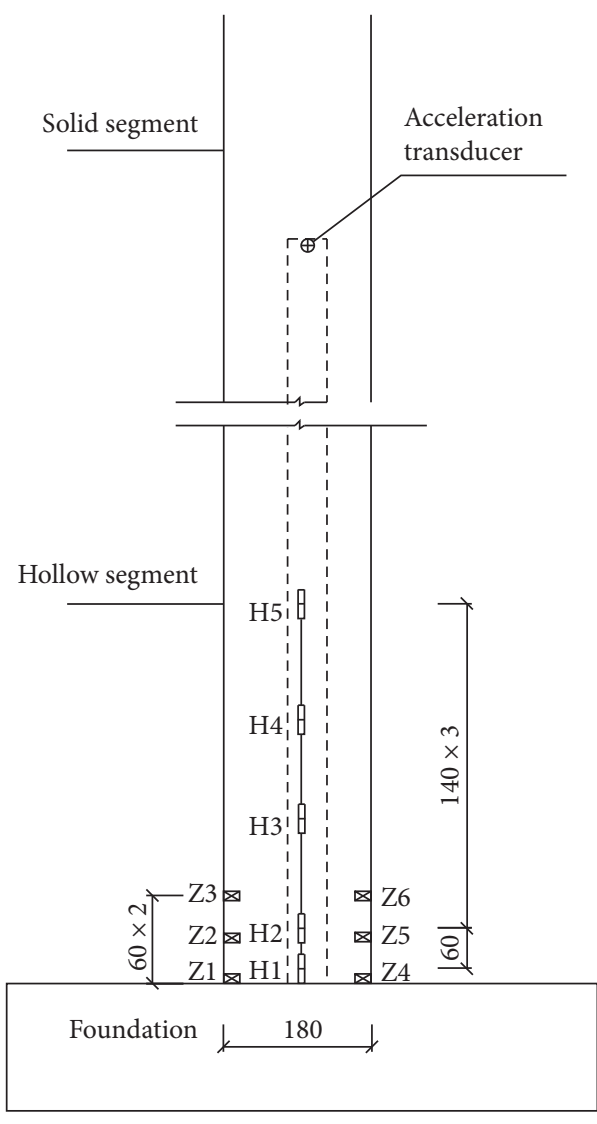

$\varangle$ Strain gauge for bar

Q Strain guage for concrete

FIgURE 4: Layout of measuring points.

periods of each group of specimens were similar. This showed that the stirrup ratio has a relatively small impact on the specimen period. Comparing M4 and M5, M6 and M9, and M7 and M8, it can be seen that the reinforcement ratio has a significant impact on the period of the specimen. The higher the reinforcement ratio is, the higher the stiffness of the specimen is and the smaller the natural vibration period is. The higher the axial compression ratio is, the higher the vibration period is. In addition, it can be seen from the figure that the period of the M5 specimen was the largest after $1.2 \mathrm{~g}$, which indicated that the stiffness of the M5 specimen decreased most obviously and the damage was more serious. The results showed that high axial compression ratio, low reinforcement ratio, and low stirrup ratio have adverse effects on the period of specimens.

3.4. Damping Ratio of Specimen. Damping mainly affects the decay rate of structural free vibration. The higher the damping ratio is, the higher the decay rate of the structure is. The damping ratio of pier specimens can be obtained by analysing the peak displacement point at the pier top when free vibration occurs. It can be computed as follows:

$$
\xi=\frac{1}{2 \pi j} \ln \frac{u_{i}}{u_{i+j}},
$$


TABle 5: Loading conditions.

\begin{tabular}{|c|c|c|}
\hline Condition number & $\begin{array}{l}\text { Peak value of input ground } \\
\text { motion wave }(\mathrm{g})\end{array}$ & $\begin{array}{l}\text { Input ground motion } \\
\text { wave }\end{array}$ \\
\hline 1 & 0.035 & White noise \\
\hline 2 & & El Centro wave \\
\hline 3 & 0.25 & Taft wave \\
\hline 4 & & Artificial Lanzhou wave \\
\hline 5 & 0.035 & White noise \\
\hline 6 & & El Centro wave \\
\hline 7 & 0.5 & Taft wave \\
\hline 8 & & Artificial Lanzhou wave \\
\hline 9 & 0.035 & White noise \\
\hline 10 & & El Centro wave \\
\hline 11 & 0.75 & Taft wave \\
\hline 12 & & Artificial Lanzhou wave \\
\hline 13 & 0.035 & White noise \\
\hline 14 & & El Centro wave \\
\hline 15 & 1.0 & Taft wave \\
\hline 16 & & Artificial Lanzhou wave \\
\hline 17 & 0.035 & White noise \\
\hline 18 & & El Centro wave \\
\hline 19 & 1.2 & Taft wave \\
\hline 20 & & Artificial Lanzhou wave \\
\hline 21 & 0.035 & White noise \\
\hline
\end{tabular}

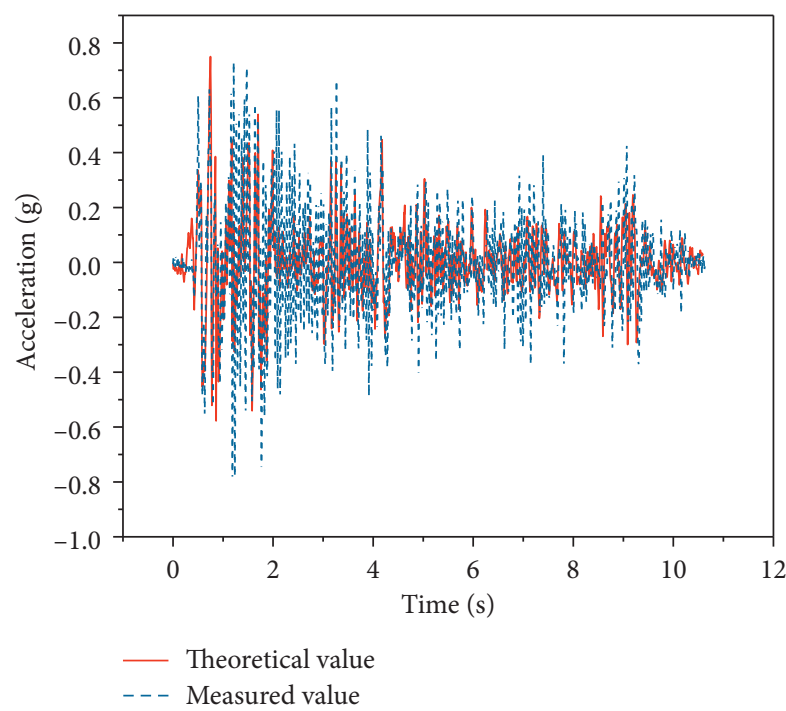

(a)

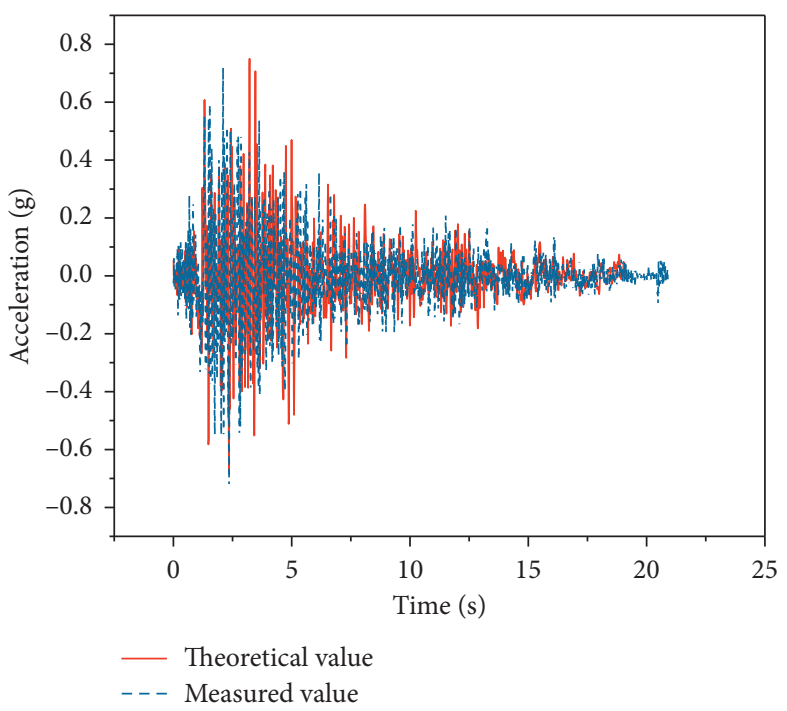

(b)

Figure 5: Continued. 


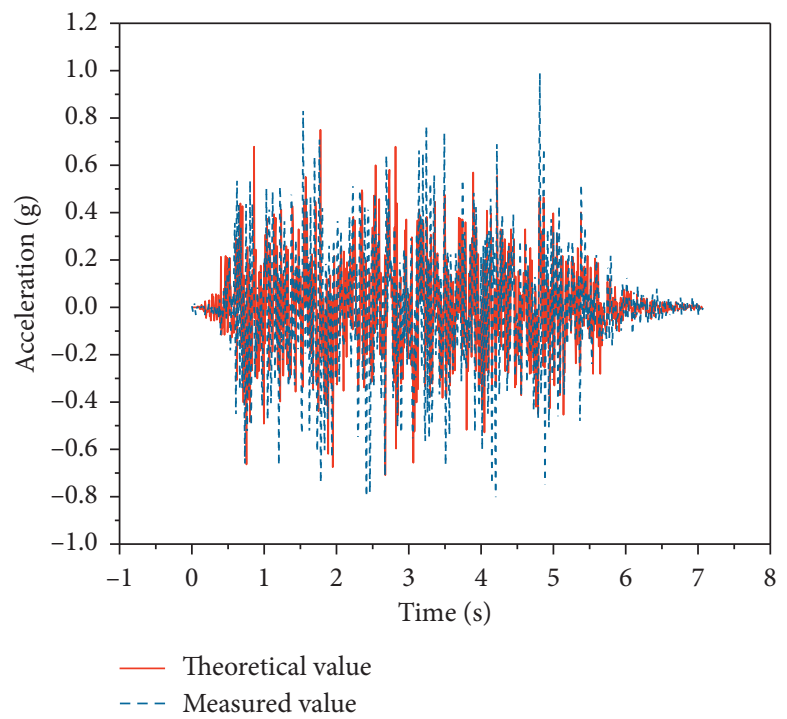

(c)

FIgURE 5: Acceleration-time history curves. (a) El Centro wave. (b) Taft wave. (c) Artificial Lanzhou wave.

TABLE 6: Failure modes.

Loading conditions $(\mathrm{g})$

0.25

0.5

0.75

1.0

1.2

Failure modes

The specimens had slight vibration, and no visible cracks appeared.

The vibration of the specimens was obvious, and there were slight cracks at the four bottom corners of the specimens. M7 produced penetrating cracks. There were some horizontal cracks in the middle and lower parts of M5, M8, and M9. Wider cracks occurred at the connection between the bottom of the column and the base of the specimen.

Shaking of the specimen became increasingly severe, and the specimen was pulled out from the base.

Previous cracks on M3 and M4 continued to extend, their widths increased, and new cracks occurred. New penetrating cracks appeared on the M7 specimen.

The previous crack continued to extend. M3, M4, M5, and M6 had penetrating cracks, the column was pulled out from the base obviously, the new cracks continued to extend upward, and the cover concrete at the root of the pier column began to spall.

Shaking of the specimen became increasingly severe. All the nine pier specimens had penetrating cracks, the number of cracks increased, and the width of cracks widened. M7 produced four through cracks when the input ground motion was $0.5 \mathrm{~g}$ and $0.75 \mathrm{~g}$. With the increase of the peak acceleration of input ground motion, the width of cracks continued to increase, but new cracks did not occur. The cracks of other specimens continued to extend to the upper part of the pier, and the number of cracks increased obviously, but all the specimens had vertical bearing capacity.

where $\xi=$ damping ratio, $u_{i}=$ the $i$ th peak displacement, and $u_{i+j}=$ the first $(i+j)$ th peak displacement.

Figure 8 shows the damping ratios of piers. It can be seen from the figure that, with the increase of the peak acceleration of the input ground motion excitation, the damping ratio of the specimens increased and ranged from 0.02 to 0.064 overall. The damping ratio was little different among the specimens. Comparing groups, it was found that the damping ratio of M4 


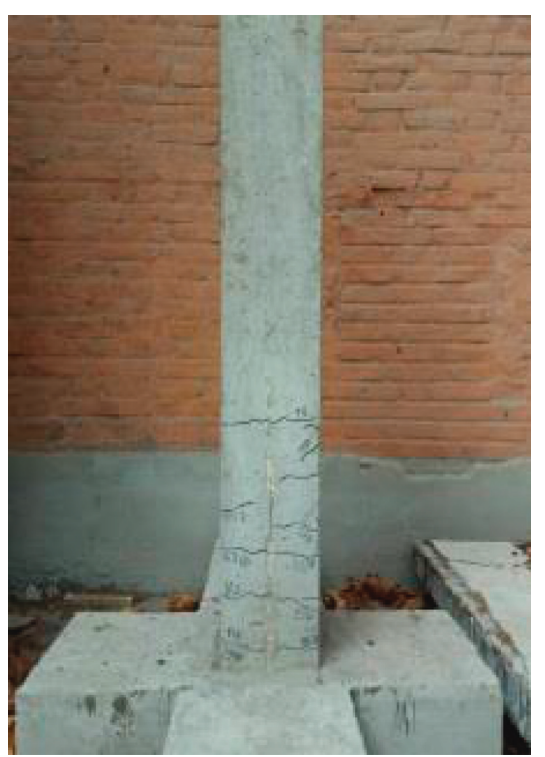

(a)

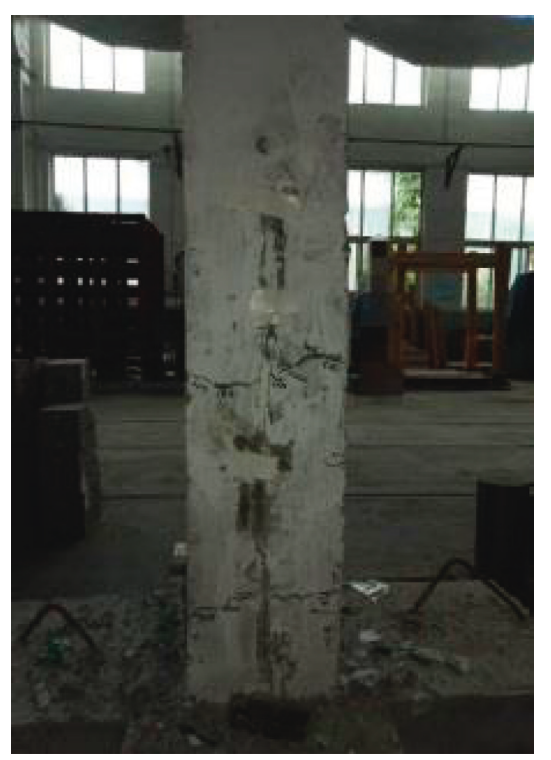

(d)

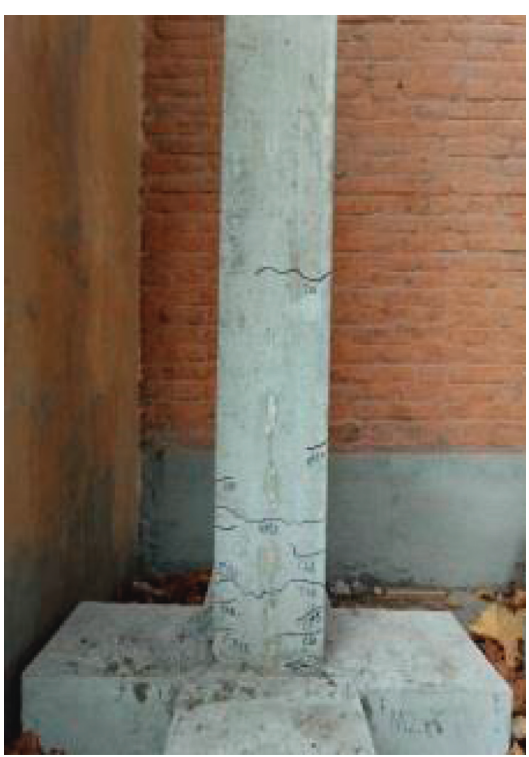

(b)

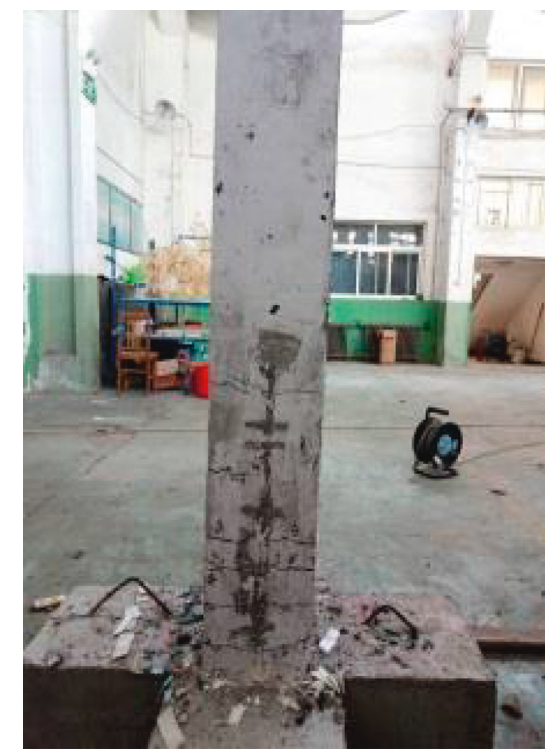

(e)

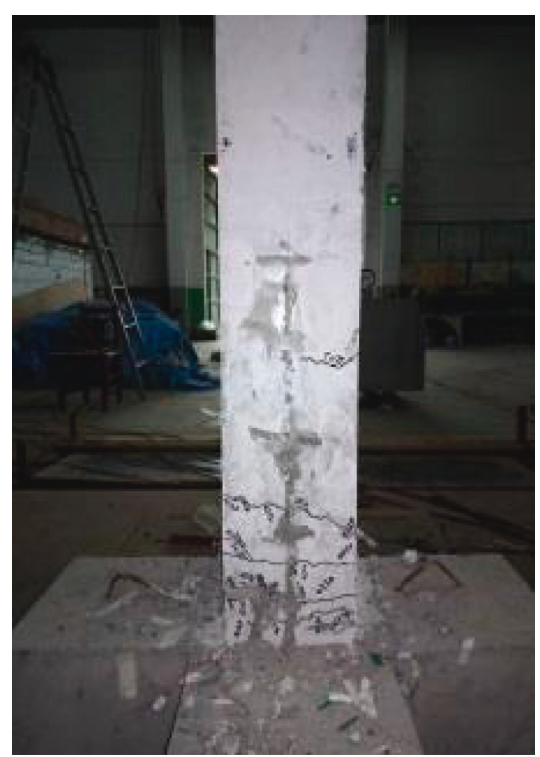

(c)

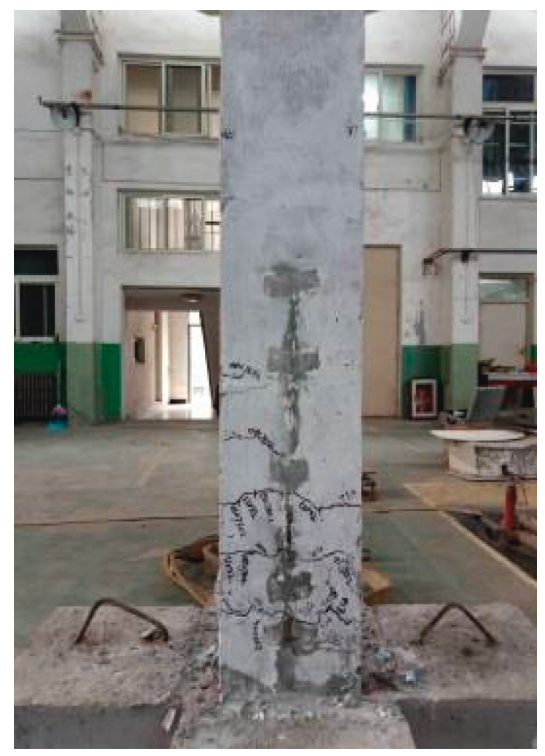

(f)

Figure 6: Continued. 


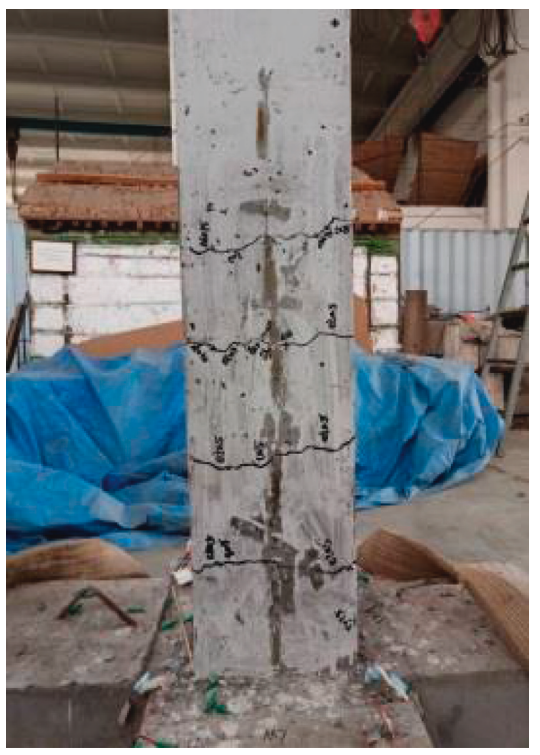

(g)

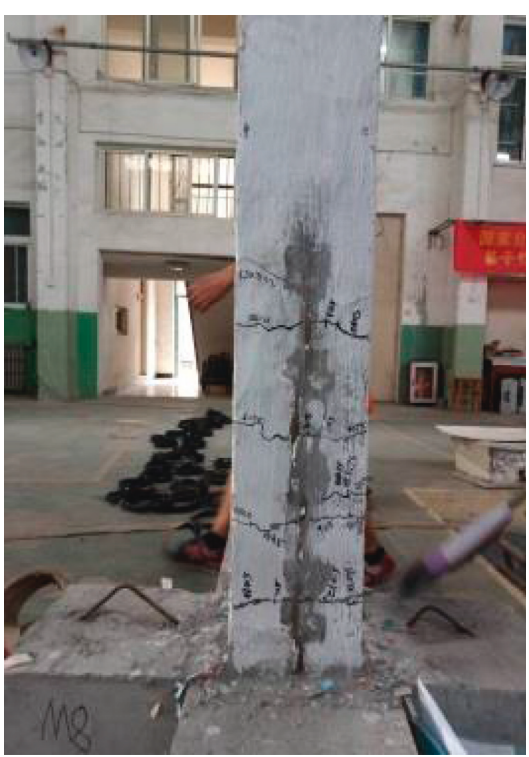

(h)

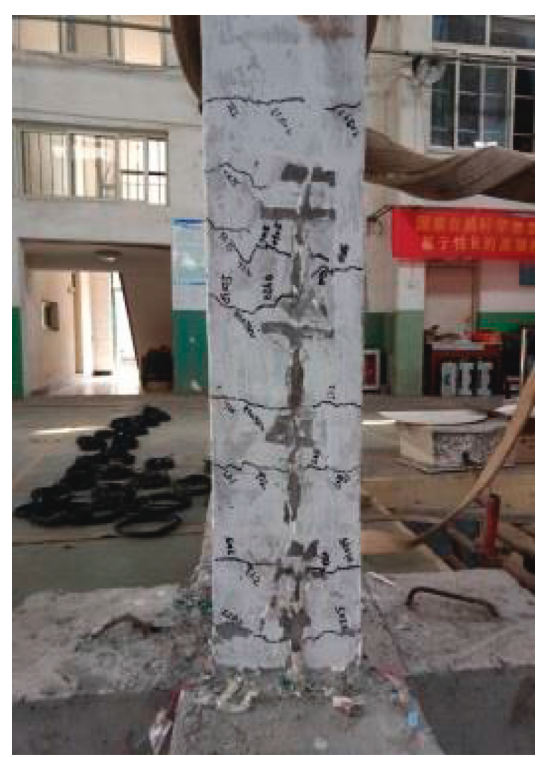

(i)

Figure 6: Distribution of postearthquake cracks of each pier: (a) M1; (b) M2; (c) M3; (d) M4; (e) M5; (f) M6; (g) M7; (h) M8; (i) M9.

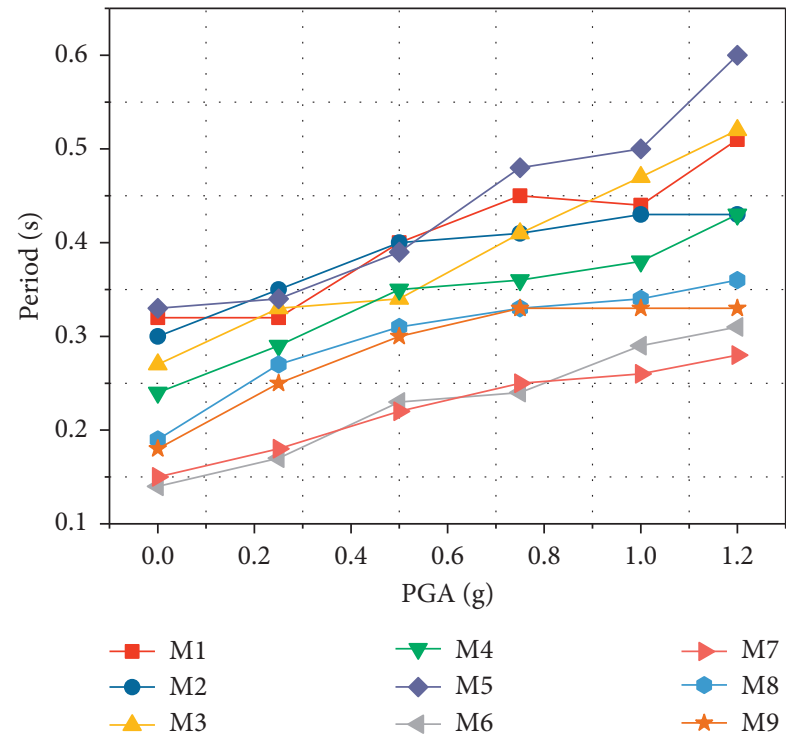

FIgURE 7: Natural vibration period of piers.

was higher than that of M5 and the damping ratio of M6 was higher than that of M9. It showed that when the axial compression ratio and stirrup ratio remain unchanged, the higher the reinforcement ratio is, the smaller the damping ratio is. Comparing M3 and M6, M4 and M7, and M5 and M8, it can be judged that, with the increase of the axial compression ratio, the damping ratio increased. Comparing M3 and M4, M6 and M7, and M8 and M9, it was found that the higher the stirrup ratio is, the higher the damping ratio of the specimen is. It indicated that the decay rate of the specimen is faster.

3.5. Acceleration Response of Piers. The acceleration of the pier top under three kinds of waves is shown in Figure 9.

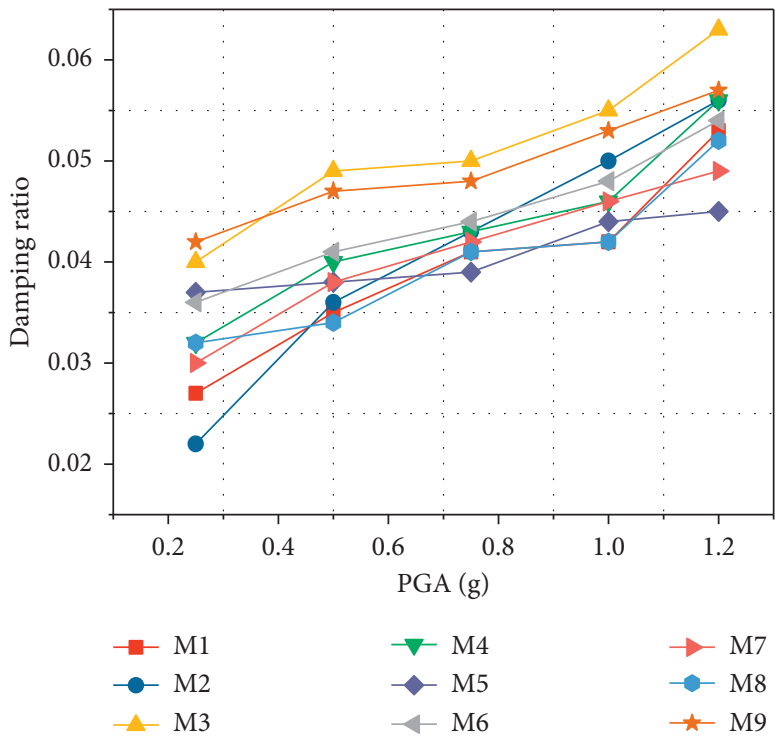

FIgURE 8: Damping ratio.

With the increase of the input ground motion excitation, the maximum acceleration of the pier top increased. The acceleration-time history curves of M6 specimens under working conditions 10 (El Centro $0.75 \mathrm{~g}$ ), 11 (Taft $0.75 \mathrm{~g}$ ), and 12 (Taft $0.75 \mathrm{~g}$ ) are listed, as shown in Figure 10.

Comparing M4 and M5, M6 and M9, and M7 and M8, it was shown that the pier top extreme acceleration of the former was bigger than that of the latter, which showed that when the axial compression ratio and stirrup ratio are the same, the higher the longitudinal reinforcement ratio is, the bigger the pier top extreme acceleration is. Taking the Taft wave as an example, when the PGA was $0.25 \mathrm{~g}$, with the decrease of the longitudinal reinforcement ratio, the three extreme accelerations declined by $30 \%, 44 \%$, and $21 \%$, 


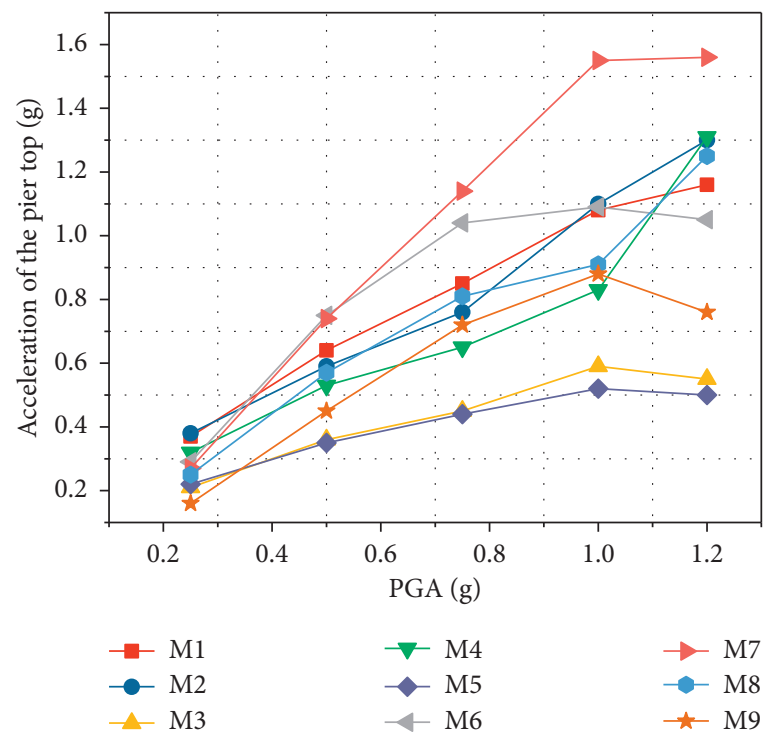

(a)

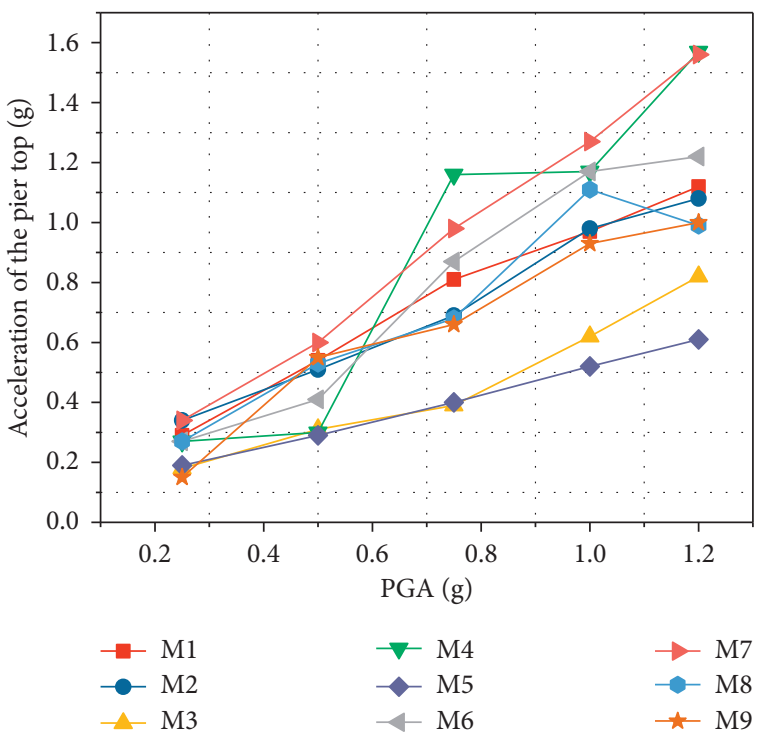

(b)

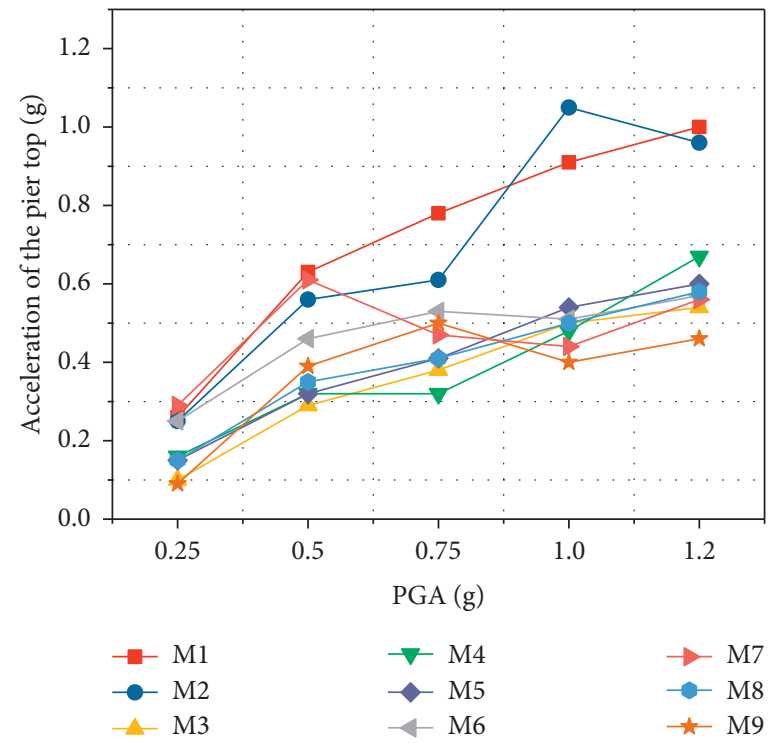

(c)

FIgURE 9: Acceleration response on the pier top under different ground motion waves. (a) El Centro wave. (b) Taft wave. (c) Artificial Lanzhou wave.

respectively; when the PGA was $0.75 \mathrm{~g}$, the three extreme accelerations declined by $66 \%, 24 \%$, and $31 \%$, respectively; when the PGA was $1.0 \mathrm{~g}$, the three extreme accelerations declined by $56 \%, 21 \%$, and $13 \%$, respectively. It showed that, under the action of high axial compression ratio, the extreme acceleration of the pier top decreased sharply when the reinforcement ratio decreased, which indicated that the longitudinal reinforcement ratio has a more obvious effect on pier top extreme acceleration at high axial compression ratio, while the stirrup ratio has little effect on the pier top extreme acceleration.

Comparing M3 and M6, M4 and M7, and M5 and M8, it can be seen that the former was smaller than the latter, indicating that the maximum acceleration of the pier top increased with the decrease of the axial compression ratio.
This is because the upper mass decreased, the period of the specimen decreased, and the acceleration response of the pier top increased.

Comparing M3 and M4, M6 and M7, and M8 and M9, it can be seen that, with the increase of the stirrup ratio, the peak acceleration of the pier top decreased. This tendency is obvious under El Centro waves and Taft waves, but the effect of stirrups under artificial Lanzhou waves is not obvious. The effect of stirrups is more obvious at high axial compression ratio.

3.6. Displacement Response of Pier Top. The extreme displacement of the pier top of each specimen is shown in Figure 11. Figure 12 shows the pier top displacement-time 


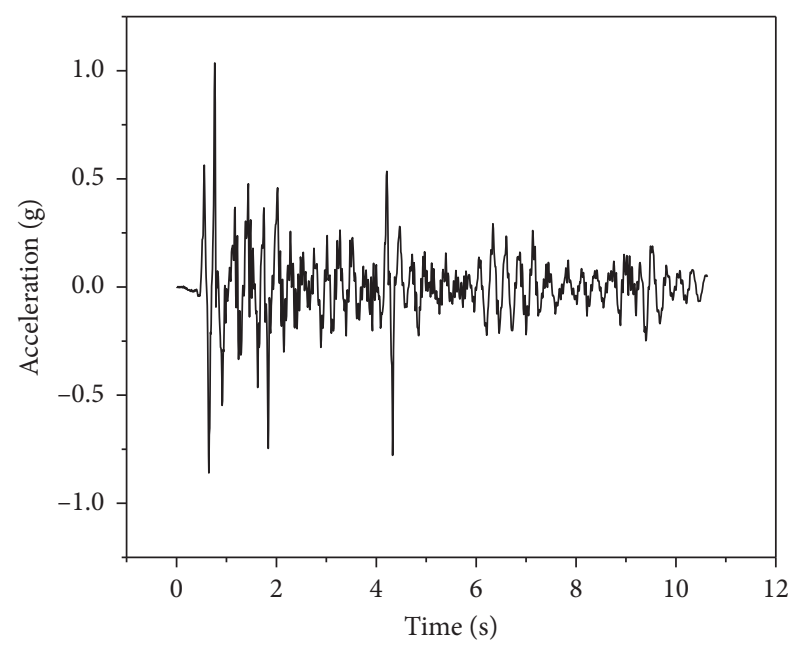

(a)

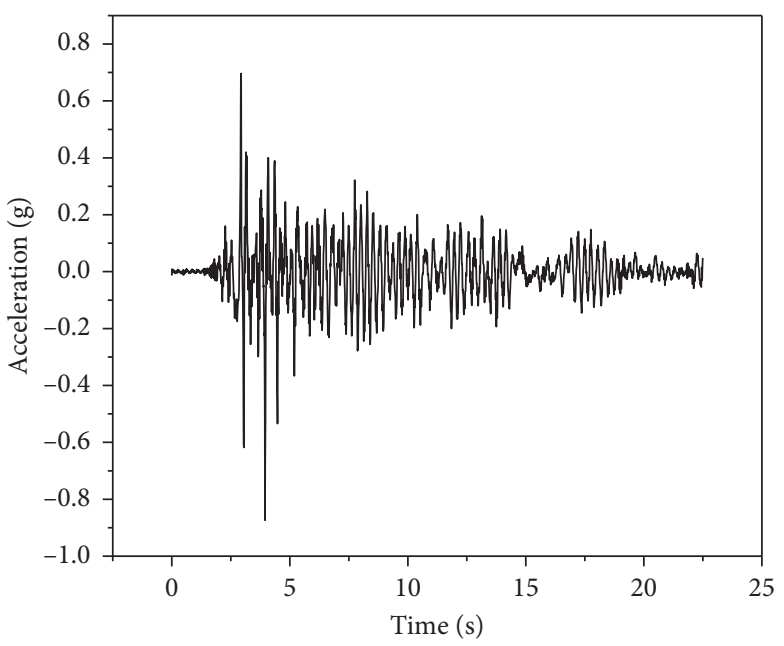

(b)

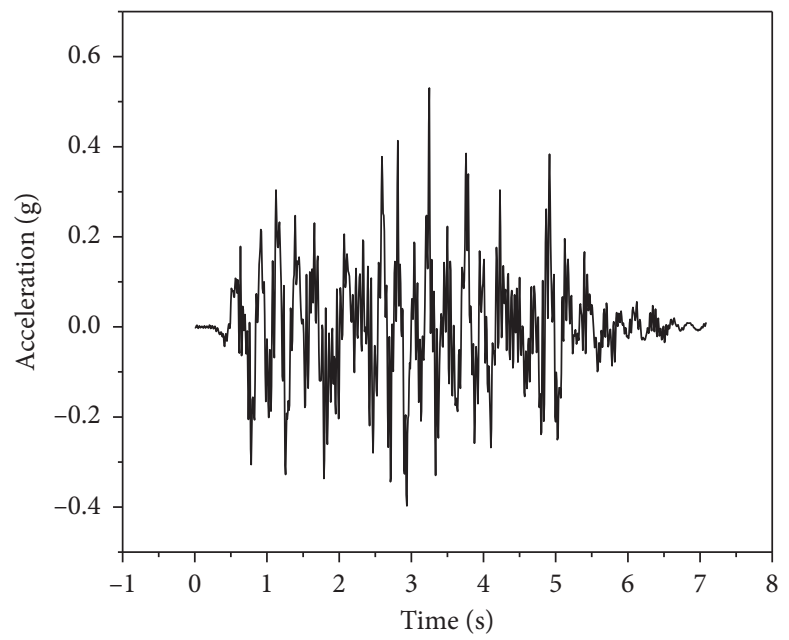

(c)

FIgUre 10: Acceleration-time history curve of the pier top. (a) El Centro wave. (b) Taft wave. (c) Artificial Lanzhou wave.

history curve of the M6 specimen at $0.75 \mathrm{~g}$. It can be seen that the displacement of the pier top increased with the increase of the PGA. Increasing reinforcement ratios can reduce displacement of the pier top. The higher the axial compression ratio, the bigger the displacement response of the pier top, and the increase of the displacement of the pier top was at least $20 \%$. The higher the stirrup ratio is, the bigger the extreme displacement of the pier top is.

3.7. Dynamic Magnification Factor. Dynamic magnification factor is the ratio of the maximum absolute acceleration response of the specimen to the maximum input ground motion acceleration. The dynamic magnification factor after each stage is shown in Figure 13. With the increase of the input ground motion excitation, the damage of pier specimens accumulated and the period increased, so the dynamic magnification factor decreased. It can be seen from Figure 13 that the bigger the reinforcement ratio is, the bigger the stiffness of the specimen is and the bigger the dynamic magnification factor is. With the increase of the axial compression ratio, the upper mass increased, the period increased, and the dynamic magnification factor decreased. Increasing stirrup ratios can slow down the decreasing trend of dynamic magnification factor. The trend of dynamic magnification factor is consistent with the trend of acceleration response.

3.8. Displacement Ductility Factor. It is an important index to evaluate the seismic performance of bridges. In this paper, Shigeki's method was used to approximate the displacement ductility factor of the specimens [23]. The method assumes that the lateral displacement restoring force model of the pier top is an ideal elastic-plastic model. It can be calculated as follows:

$$
\mu=\frac{\delta_{i}}{\delta_{y}}=\frac{T_{i}^{2}}{T_{0}^{2}}
$$

where $\mu$ =displacement ductility factor, $\delta_{i}=$ maximum displacement response under seismic loading of a certain intensity, $\delta_{y}=$ yield displacement, $T_{i}=$ natural vibration 


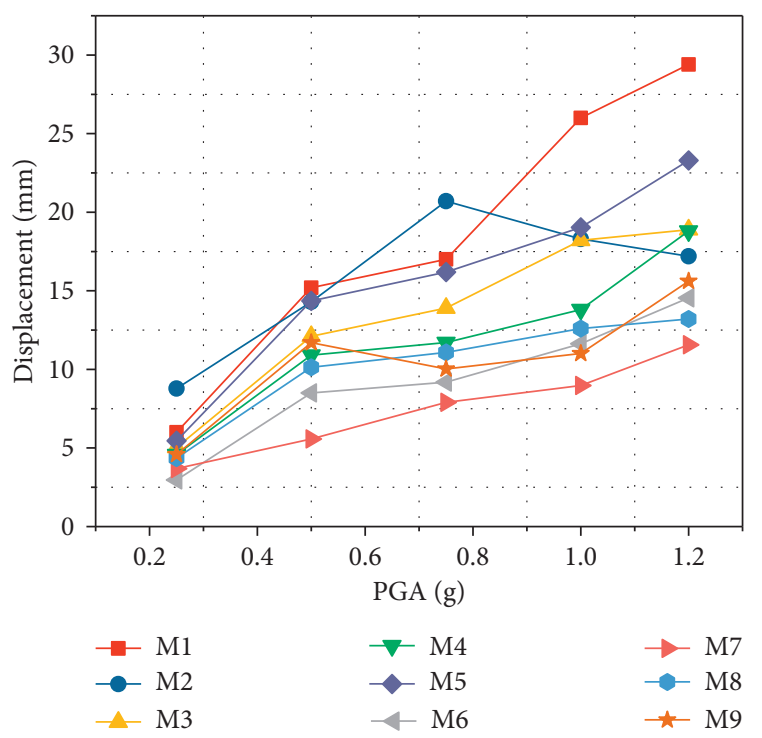

(a)

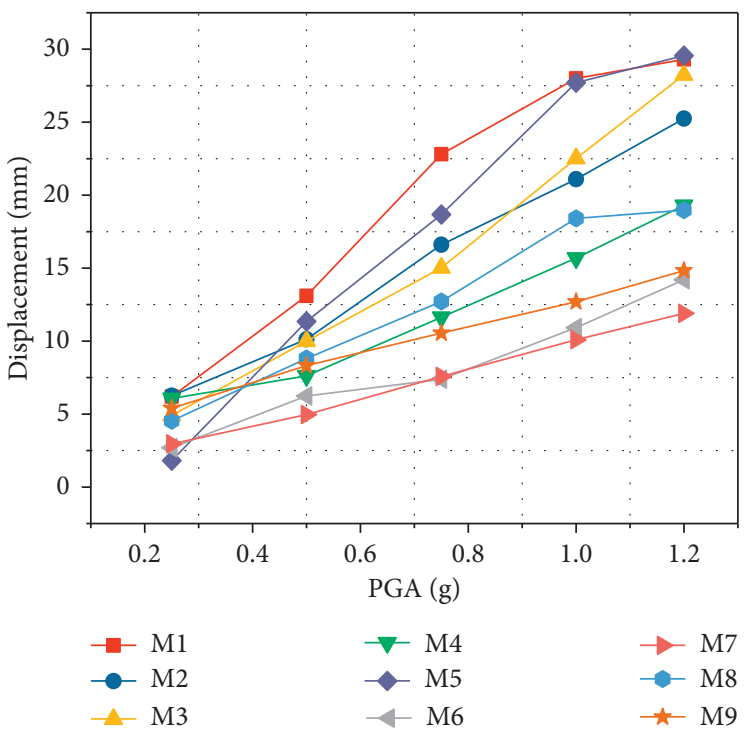

(b)

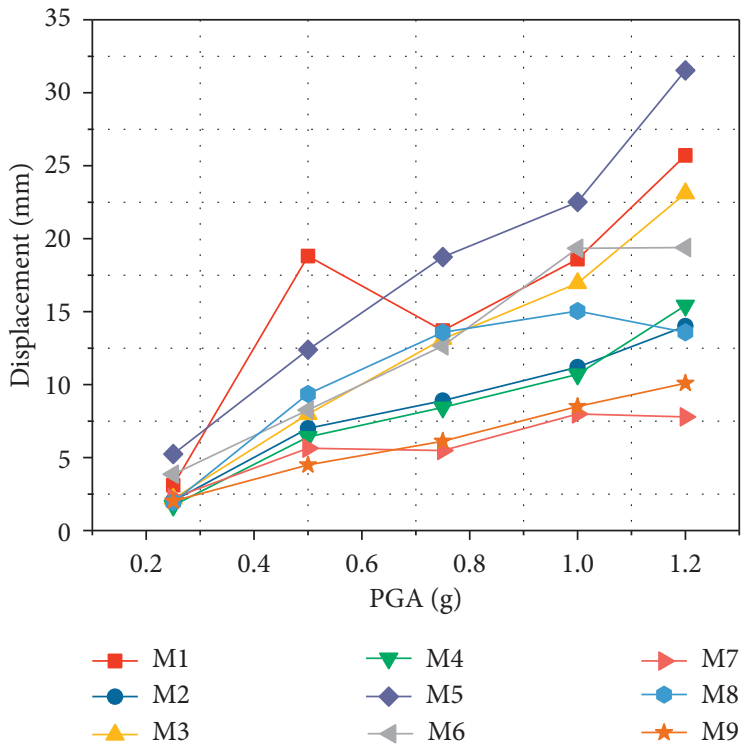

(c)

Figure 11: Displacement response on the pier top under different ground motion waves. (a) El Centro wave. (b) Taft wave. (c) Artificial Lanzhou wave.

period after certain working conditions, and $T_{0}=$ natural vibration period before loading.

The displacement ductility factor obtained is shown in Figure 14.

It can be seen that the displacement ductility factor increased with the increase of the PGA. The displacement ductility coefficients of all pier specimens were between 1.0 and 5.0. Increasing reinforcement ratios and stirrup ratios can increase the displacement ductility factor of pier specimens, and increasing axial compression ratios can reduce the displacement ductility factor.

3.9. Energy Dissipation of Specimens. The energy dissipation capacity of piers is an important parameter to measure the seismic performance of piers. The better the energy dissipation capacity is, the better the seismic performance of piers is. In this test, the piers can be calculated according to the SDOF system. The energy balance equation of the nonlinear SDOF system is as follows:

$$
\begin{aligned}
& \int_{0}^{t} m \ddot{u}(t) \dot{u}(t) d t+\int_{0}^{t} c \ddot{u}(t) \dot{u}(t) d t+\int_{0}^{t} k \ddot{u}(t) \dot{u}(t) d t \\
& =-\int_{0}^{t} m \ddot{u}_{g}(t) \dot{u}(t) d t .
\end{aligned}
$$

Simplifying formula (3) yields the following formula:

$$
E_{\mathrm{k}}(t)+E_{\mathrm{D}}(t)+E_{\mathrm{s}}(t)+E_{\mathrm{H}}(t)=E_{\mathrm{I}}(t) .
$$

Formula (4) corresponds to formula (3), where $E_{\mathrm{k}}(t)=$ kinetic energy of the SDOF system, $E_{\mathrm{D}}(t)=$ structural 


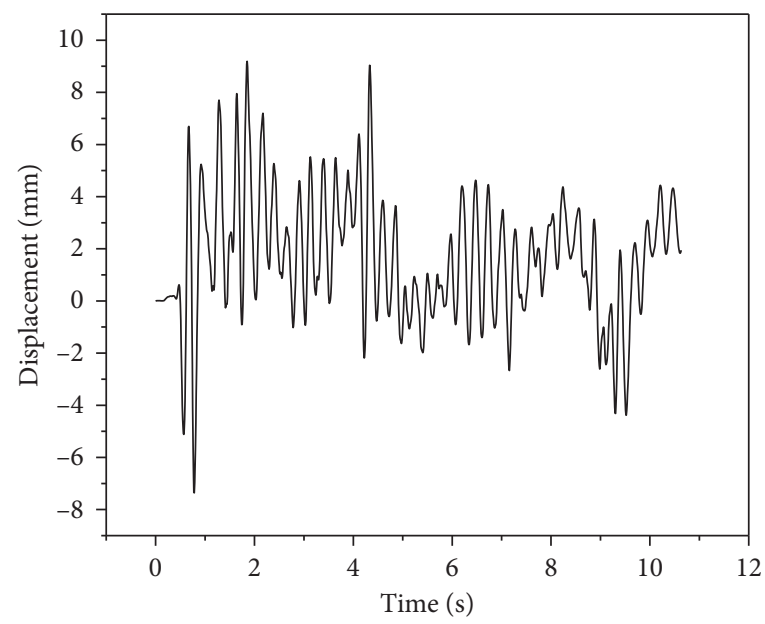

(a)

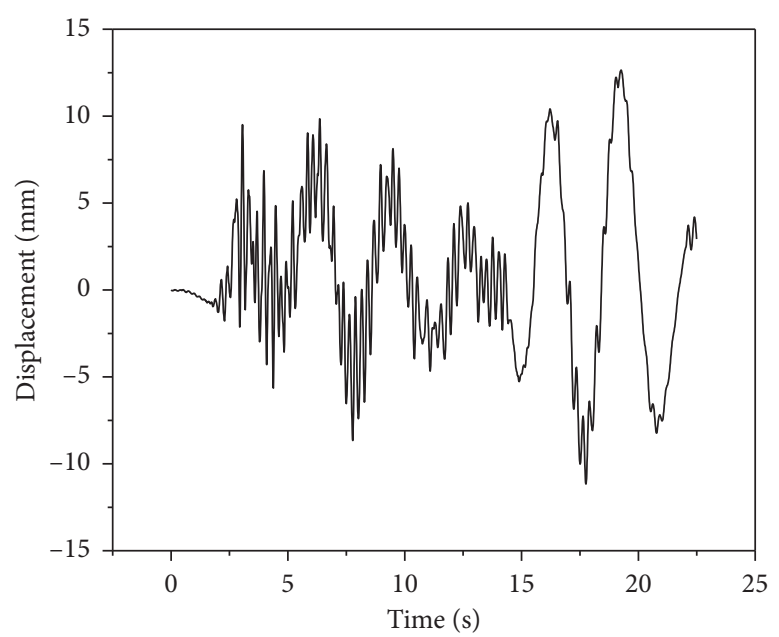

(b)

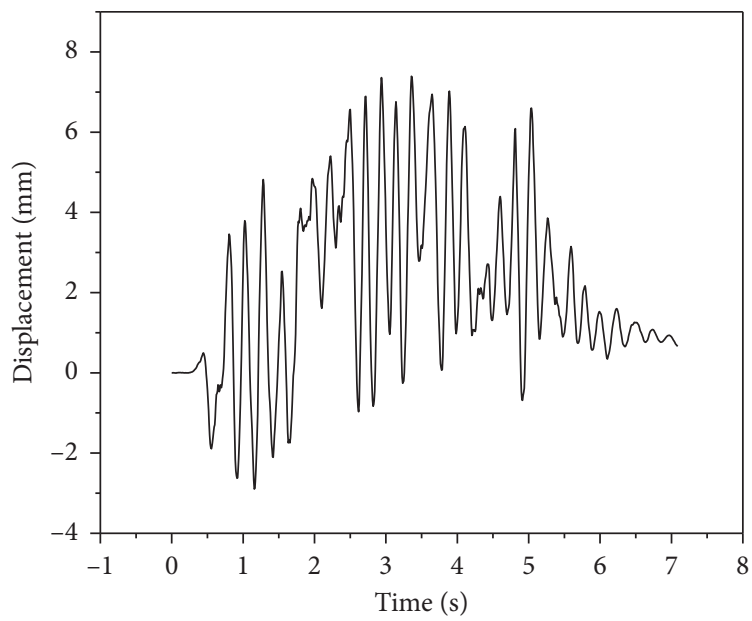

(c)

Figure 12: Displacement-time history curve of the pier top. (a) El Centro wave. (b) Taft wave. (c) Artificial Lanzhou wave.

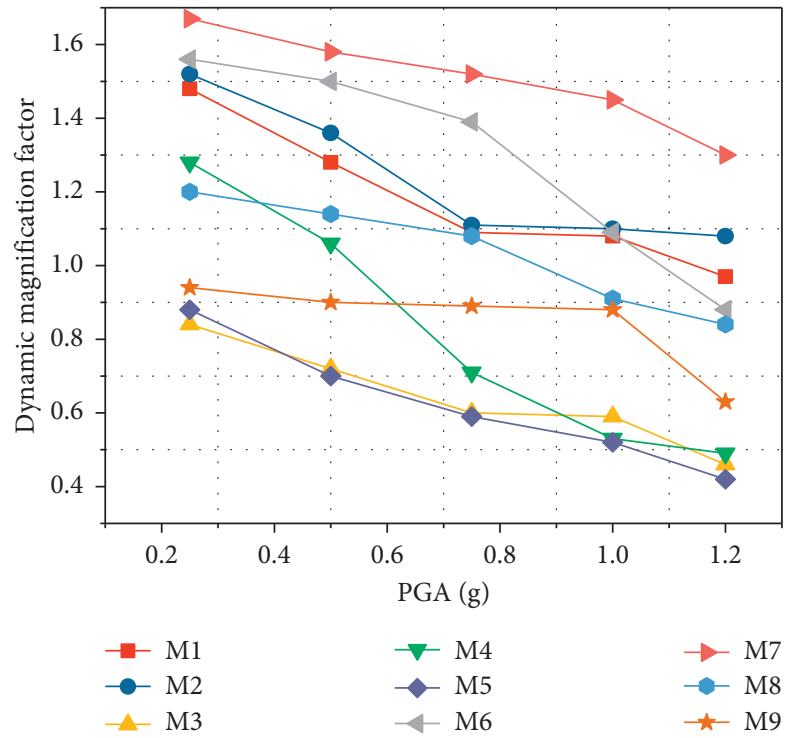

FIGURE 13: Dynamic magnification factor.

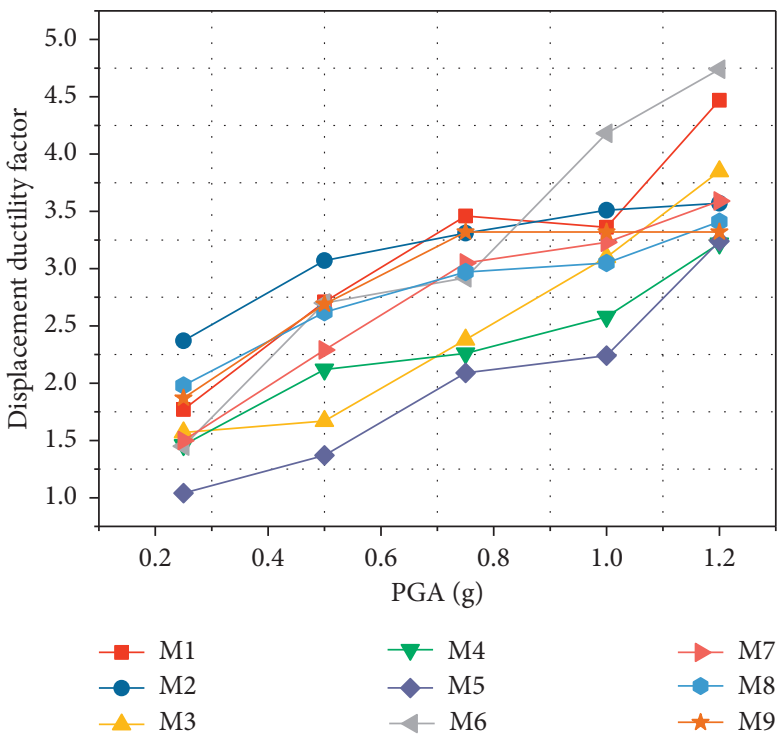

FIgURE 14: Displacement ductility factor. 


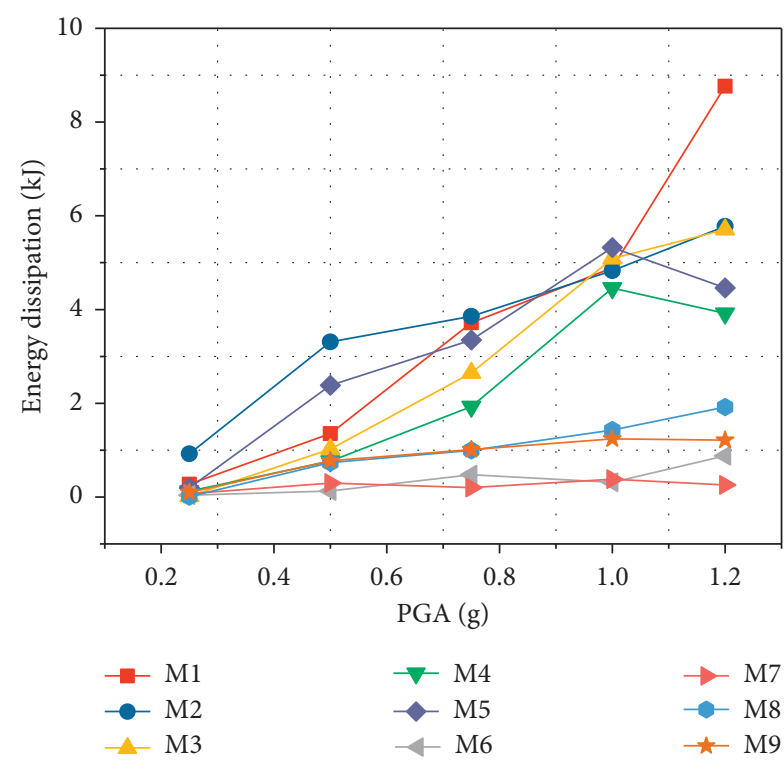

FIgURe 15: Energy dissipation of each pier specimen.

damping energy dissipation, $E_{\mathrm{s}}(t)=$ elastic deformation energy, $E_{\mathrm{H}}(t)=$ hysteretic energy, and $E_{\mathrm{I}}(t)=$ total input seismic energy. When the earthquake excitation ends, $E_{\mathrm{k}}(t)=0$ and $E_{\mathrm{s}}(t)=0$, so formula (4) is transformed as follows:

$$
E_{\mathrm{D}}\left(t_{\mathrm{e}}\right)+E_{\mathrm{H}}\left(t_{\mathrm{e}}\right)=E_{\mathrm{I}}\left(t_{\mathrm{e}}\right)
$$

Therefore, the total input seismic energy is the total energy dissipation of pier specimens. Energy dissipation of each pier specimen is shown in Figure 15. It can be seen that the energy dissipation of each specimen increased with the increase of the PGA. The energy dissipation of M1-M5 piers was higher than that of M6-M9, which indicated that increasing the axial compression ratio can increase the energy dissipation of piers, especially when the input ground motion excitation is stronger, and the energy dissipation of the specimen increased significantly with the increase of the axial compression ratio.

Comparing M1, M2, M3, and M4, it was found that the stirrup ratio of the four specimens decreased in turn, and the energy dissipation of the specimens decreased. It can be seen that the energy dissipation of the specimens increased with the increase of the stirrup ratio. Under the action of high axial compression ratio, the effect of stirrups on energy dissipation of specimens is more obvious.

It can also be seen that the energy dissipation of M5, M9, and M8 was bigger than that of M4, M6, and M9, respectively. The results showed that the higher the reinforcement ratio is, the smaller the total seismic input energy is and the smaller the energy dissipation of the specimen is.

\section{Conclusions}

In this paper, nine hollow rectangular reinforced concrete pier columns with a geometric similarity ratio of $1 / 8$ were designed and fabricated. The El Centro wave, Taft wave, and artificial Lanzhou wave were selected as seismic excitation for the shaking table test to study the influence of different parameters on the seismic performance of hollow piers. The following conclusions are drawn from this study:

(1) With the increase of the PGA, cracks continued to develop and gradually became deeper and wider. Horizontal cracks were dominant under the action of ground motion excitation, in accordance with the bending failure mode. The period of piers increased continuously. The period of all specimens did not exceed $0.62 \mathrm{~s}$, and the damping ratio ranged from 0.02 to 0.064 .

(2) The dynamic amplification factor of the pier specimen decreased with the increase of the PGA and increased with the increase of the reinforcement ratio.

(3) The pier top acceleration response increased with the increase of the reinforcement ratio and decreased with the increase of the axial compression ratio and stirrup ratio, but the stirrup ratio had a relatively small impact on pier top acceleration response. The reinforcement ratio had a more obvious influence on pier performance at high axial compression ratio.

(4) The displacement of the pier top increased with the increase of the PGA, decreased with the increase of the reinforcement ratio, and increased with the increase of the axial compression ratio and stirrup ratio.

(5) With the increase of the PGA, the displacement ductility factor of pier specimens increased. The energy consumption of pier specimens increased with the increase of the stirrup ratio and axial compression ratio and decreased with the increase of the reinforcement ratio.

(6) The axial compression ratio, reinforcement ratio, and stirrup ratio have evident effects on the ductility of the pier columns. Therefore, it is suggested that the axial compression ratio should be limited and the reinforcement ratio and stirrup ratio should be properly increased in the design of hollow rectangular piers in the future.

\section{Data Availability}

The data used to support the findings of this study are available from the corresponding author upon request.

\section{Conflicts of Interest}

The authors declare that there are no conflicts of interest regarding the publication of this paper.

\section{Acknowledgments}

This research was funded by the National Natural Science Fund of China (NSFC) (grant no. 51378169) and Natural Science Foundation of Hebei Province in China (E2013402072). 


\section{References}

[1] X. Du and Q. Han, "Research progress on seismic design of bridges," Earthquake Engineering and Engineering Vibration, vol. 34, no. 4, pp. 1-14, 2014.

[2] J. S. Matthew, A Full-Scale, Single-Column Bridge Bent Tested by Shake-Table Excitation, PEER, Berkeley, CA, USA, 2015.

[3] J. Sakai and S. Unjoh, "Shake table experiment on circular reinforced concrete bridge column under multidirectional seismic excitation," in Proceedings of the Research Frontiers at Structures Congress, vol. 5, no. 249, pp. 1-12, Long Beach, CA, USA, May 2007.

[4] G. M. Calvi, A. Pavese, A. Rasulo, and D. Bolognini, "Experimental and numerical studies on the seismic response of R.C. hollow bridge piers," Bulletin of Earthquake Engineering, vol. 3, no. 3, pp. 267-297, 2005.

[5] Y. L. Mo and I. C. Nien, "Seismic performance of hollow highstrength concrete bridge columns," Journal of Bridge Engineering, vol. 7, no. 6, pp. 338-349, 2002.

[6] Y.-K. Yeh, Y. L. Mo, and C. Y. Yang, "Seismic performance of rectangular hollow bridge columns," Journal of Structural Engineering, vol. 128, no. 1, pp. 60-68, 2002.

[7] Y. K. Yeh, Y. L. Mo, and C. Y. Yang, "Seismic performance of hollow circular bridge piers," ACI Structure Journal, vol. 98, no. 6, pp. 862-871, 2001.

[8] Y.-K. Yeh, Y. L. Mo, and C. Y. Yang, "Full-scale tests on rectangular hollow bridge piers," Materials and Structures, vol. 35, no. 2, pp. 117-125, 2002.

[9] A. V. Pinto, J. Molina, and G. Tsionis, "Cyclic tests on largescale models of existing bridge piers with rectangular hollow cross-section," Earthquake Engineering \& Structural Dynamics, vol. 32, no. 13, pp. 1995-2012, 2003.

[10] P. Cassese, P. Ricci, and G. M. Verderame, "Experimental study on the seismic performance of existing reinforced concrete bridge piers with hollow rectangular section," Engineering Structures, vol. 144, pp. 88-106, 2017.

[11] P. Cassese, M. T. De Risi, and G. M. Verderame, "Seismic assessment of existing hollow circular reinforced concrete bridge piers," Journal of Earthquake Engineering, vol. 6, pp. 1-36, 2018.

[12] B. Si, H. Li, D. Wang et al., "Experimental evaluation of the seismic performance of reinforced concrete bridge piers designed on the basis of displacement (I): quasi-static test," Earthquake Engineering and Engineering Vibration, vol. 28, no. 1, pp. 123-129, 2008.

[13] Q. Ai, H. Li, D. Wang et al., "Experimental evaluation of seismic performance of reinforced concrete bridge piers designed on the basis of displacement (II): shaking table test," Earthquake Engineering and Engineering Vibration, vol. 28, no. 3, pp. 39-46, 2008.

[14] H. Wang, "Influence of reinforcement ratio on seismic response of round-ended bridge pier in high speed railway," School of Civil Engineering, Central South University, Changsha, China, Master dissertation, 2014.

[15] Z. Zhou, "The influence of shear-span ration on the seismic response of round-ended solid piers in high speed rail," School of Civil Engineering, Central South University, Changsha, China, Master dissertation, 2014.

[16] Y. Shen and S. Gu, "Shake table test for reinforced concrete hollow rectangular pier," Journal of Architecture and Civil Engineering, vol. 35, no. 5, pp. 128-133, 2018.

[17] X. Du, M. Chen, and Q. Han, "Experimental evaluation of seismic performance of reinforced concrete hollow bridge columns," Journal of Vibration and Shock, vol. 30, no. 11, pp. 254-259, 2011.

[18] L. Jiang, G. Shao, J. Jiang et al., "Experimental study on seismic performance of solid piers with round ended crosssection in high-speed railway," China Civil Engineering Journal, vol. 46, no. 3, pp. 86-95, 2013.

[19] L. Jiang, G. Shao, and H. Wang, "Experimental study on seismic performance of hollow piers with rounded rectangular cross section in high-speed railways," Engineering Mechanics, vol. 31, no. 3, pp. 72-82, 2014, in Chinese.

[20] Q. Han, Y. Zhou, and X. Du, "Seismic performance of reinforced concrete rectangular hollow bridge columns," Engineering Mechanics, vol. 32, no. 3, pp. 28-40, 2015, in Chinese.

[21] J. Li, Introduction to Earthquake Engineering, Seismological Press, Beijing, China, 1992.

[22] M. Zhang, "Study on similitude laws for shaking table tests," Earthquake Engineering and Engineering Vibration, vol. 17, no. 2, pp. 52-58, 1997, in Chinese.

[23] S. Unjoh and H. Kobayashi, "Development of an earthquake damage detection system for bridge structures," in Proceedings of North American Euro Pacific Workshop for Sensing Issues in Civil Structural Health Monitoring, pp. 165-174, Honolulu, HI, USA, January 2005. 


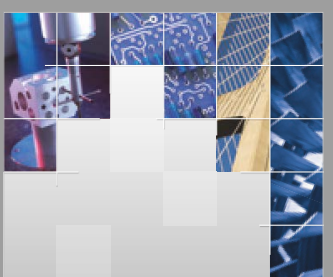

\section{Enfincering}
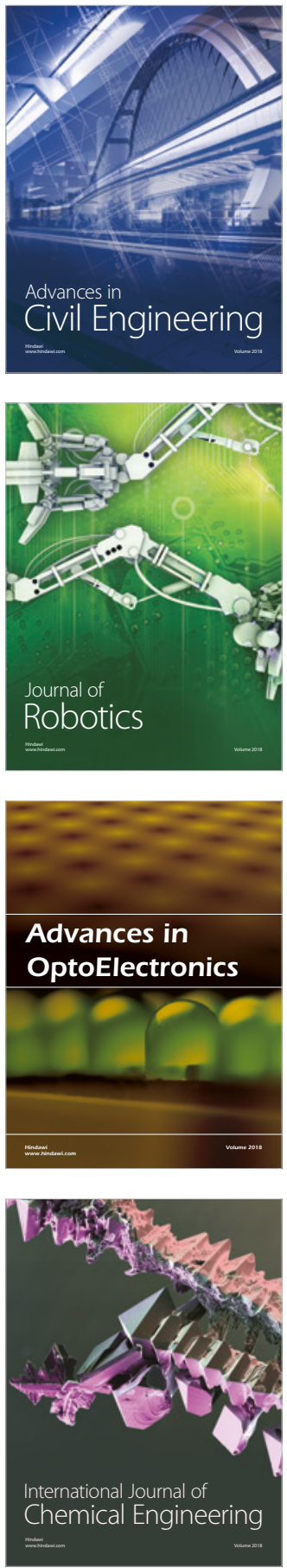

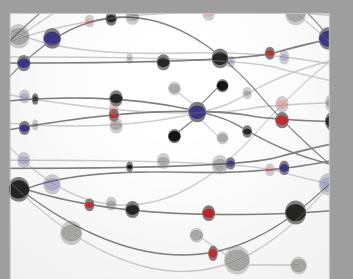

\section{Rotating \\ Machinery}

The Scientific World Journal

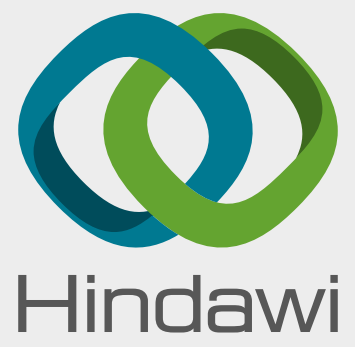

Submit your manuscripts at

www.hindawi.com
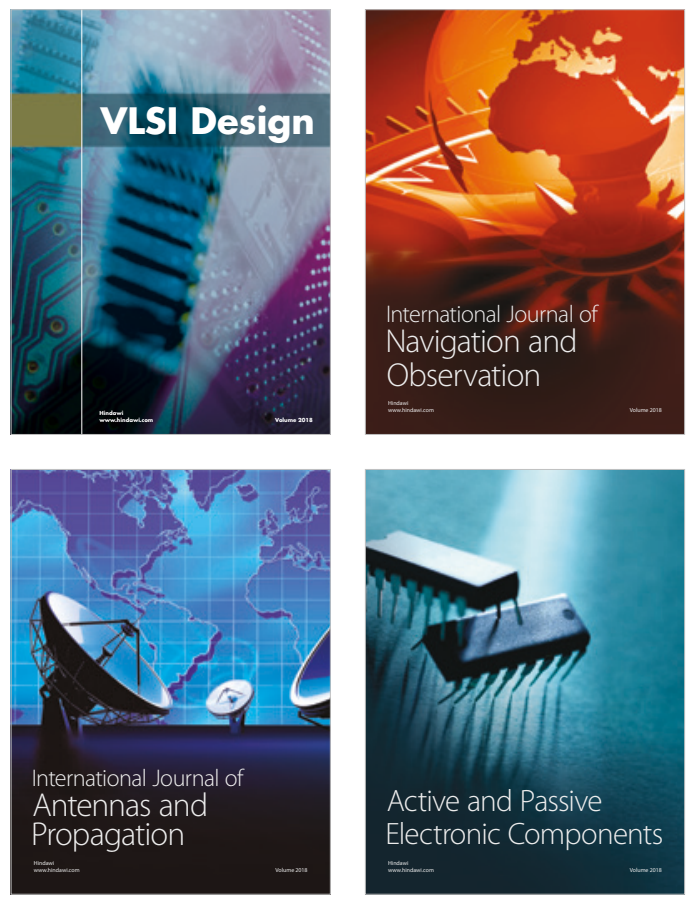
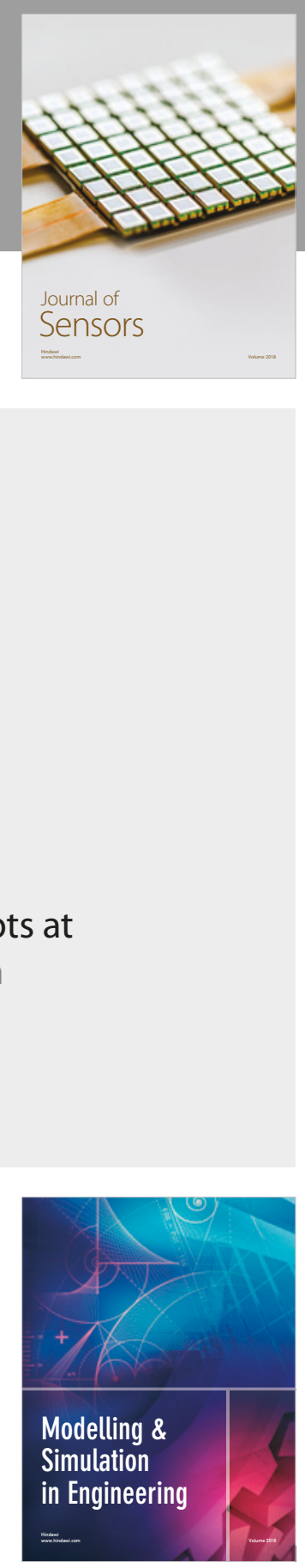

\section{Advances \\ Multimedia}
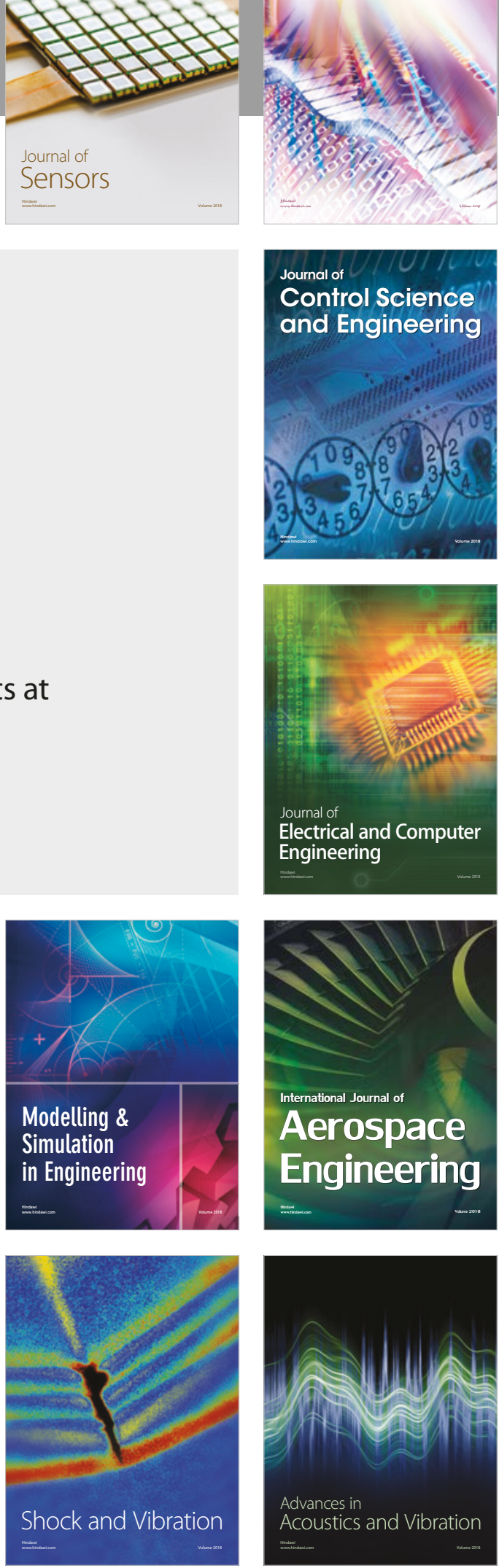